WORKING PAPER NO. 13

Oct 1996

\title{
Assessing People's Perceptions of Forests in Danau Sentarum Wildlife Reserve
}

\author{
Carol J. Pierce Colfer, Joseph Woelfel, Reed L. Wadley, \\ and Emily Harwell
}

\begin{abstract}
Summary
Previous research identified three important issues of relevance to forest people's roles in sustainable forest management which we address here: the presence of a "conservation ethic", a feeling of closeness to the forest, and a significant forest-culture link. In this paper we examine a method (the Galileo), recently pre-tested for this purpose in West Kalimantan, which we hope can help us to assess such issues quickly, reliably and in a quantitative manner amenable to use by would-be assessors of various educational and experiential levels. We describe the method, suggest improvements for future tests, and present some of our findings from West Kalimantan. We conclude with questions that emerged during our pre-test, and others that remain for subsequent research.
\end{abstract}

\section{CENTER FOR INTERNATIONAL FORESTRY RESEARCH}

office address: Jalan CIFOR, Situ Gede, Sindangbarang, Bogor 16680, Indonesia mailing address: P.O. Box 6596 JKPWB, Jakarta 10065, Indonesia

tel.: +62 (251) 622622 fax: +62 (251) 622100

email: cifor@cgnet.com

$W W W$ : http://www.cgiar.org/cifor 


\section{The CGIAR System}

The Consultative Group on International Agricultural Research (CGIAR) is an informal association of 41 public and private sector donors that supports a network of sixteen international agricultural research institutes, CIFOR being the newest of these. The Group was established in 1971. The CGIAR Centers are part of a global agricultural research system which endeavour to apply international scientific capacity to solution of the problems of the world's disadvantaged people.

\section{CIFOR}

CIFOR was established under the CGIAR system in response to global concerns about the social, environmental and economic consequences of loss and degradation of forests. It operates through a series of highly decentralised partnerships with key institutions and/or individuals throughout the developing and industrialised worlds. The nature and duration of these partnerships are determined by the specific research problems being addressed. This research agenda is under constant review and is subject to change as the partners recognise new opportunities and problems. 
CENTER FOR INTERNATIONAL FORESTRY RESEARCH

office address: Jalan CIFOR, Situ Gede, Sindangbarang, Bogor 16680, Indonesia mailing address: P.O. Box 6596 JKPWB, Jakarta 10065, Indonesia

tel.: +62 (251) 622622 fax: $+62(251) 622100$

email: cifor@cgnet.com

$W W W:$ http://www.cgiar.org/cifor 


\title{
Assessing People's Perceptions of Forests, Danau Sentarum Wildlife Reserve (West Kalimantan, Indonesia)
}

\author{
Carol J. Pierce Colfer, Joseph Woelfel, Reed L. Wadley and Emily Harwell 1
}

\begin{abstract}
Summary
Previous research identified three important issues of relevance to forest people's roles in sustainable forest management which we address here: the presence of a "conservation ethic", a feeling of closeness to the forest, and a significant forest-culture link. In this paper we examine a method (the Galileo), recently pre-tested for this purpose in West Kalimantan, which we hope can help us to assess such issues quickly, reliably and in a quantitative manner amenable to use by would-be assessors of various educational and experiential levels. We describe the method, suggest improvements for future tests, and present some of our findings from West Kalimantan. We conclude with questions that emerged during our pre-test, and others that remain for subsequent research.
\end{abstract}

\section{Introduction and Context}

To what degree do people who live in forests have a "conservation ethic"? How can we quickly and reliably assess how close people feel to the forest? How closely integrated are the lives of forest people with their environment? These are some of the questions that recurred in the context of a series of interdisciplinary, multi-locational tests on criteria and indicators for sustainable forest management, conducted by CIFOR in 1994-95. ${ }^{2}$

In this paper we report a pre-test recently conducted in four villages, among two ethnic groups in and around the Danau Sentarum Wildlife Reserve (DSWR) in West Kalimantan. We evaluate a method which we hope can help us to assess such issues more easily and reliably. After describing the method, we provide examples of the many kinds of analyses that can be made on the results. In the co3ncluding section, we discuss questions and problems that remain for further research.

\section{Method Used and Suggested}

In the pre-test described here, we conducted a conventional Galileo ${ }^{\mathrm{TM}}$ study $^{3}$ (Woelfel \& Fink, 1980) as a possible means to assess three conditions identified in previous research as relevant in establishing people's roles in sustainable forest management: The presence or absence of a "conservation ethic", a feeling of close- ness to the forest, and an intimate link between local culture and the forest.

The Galileo study begins with the identification of locally appropriate concepts pertaining to the domain of study (in this case, people-forest interactions). Because of our familiarity with the area, we knew the relevant concepts. We also included several others which we thought could help us in particular analytical questions we had. Fish, wood, rattan, honey, garden, animal, food, earth/land/soil, water, I the respondent), male, female, village/home, and money fall into the first category. Price/value, good, future, spirit, and fire fall into the second.

Such locally relevant concepts can be obtained in an unfamiliar area by content analysis of open ended interviews on the topic of interest. ${ }^{4}$ These concepts are then paired in a questionnaire format in the local language (see Appendix A for an English translation of the form used in this study).

DSWR respondents were asked to use the distance between "black" and "white" (as they saw it in their own minds) as a measuring stick, in comparing each of the study concepts (paired on the form). Literate villagers filled in the forms themselves, once they understood what they were to do; illiterates were interviewed and asked each measurement. The process, with 20 concepts, typically took 20-30 minutes.

At DSWR, we selected four communities, two Iban and two Melayu, because of the differing systems of resource use we knew them to have. We 
also tried to interview roughly equal numbers of male and female respondents in order to assess the magnitude of gender differences in perceptions of natural resources. Because of the small size of the communities, our goal was to interview every teenager and adult. There were very few refusals.

We used local people to conduct the interviews, under our supervision. Though both researchers and respondents found the task challenging, there seemed reasonably good satisfaction that the people understood what they were doing. Besides explaining the measurement concept (which was easier for the Melayu than for the Iban), it was necessary to reassure people in all communities that there was no "right" answer, that their own perceptions were the important thing. Many actually enjoyed the intellectual challenge of the task.

The data were entered by a locally hired research assistant, using the Galileo program ${ }^{5}$, during the fieldwork. Analysis took place in Bogor under the guidance of Woelfel (the principal developer of the software; Woelfel and Fink 1980; TerraVision 1995; Foldy \& Woelfel 1992), but if the other authors had known how to use the program before going to the field, it would have been easy to do it there.

The results of this procedure made it possible to represent the respondents' attitudes and beliefs in a three dimensional graph or space. This space provides a precise and holistic picture of the respondents' beliefs and attitudes about forests. Concepts which go together are close together in this space, while those that don't go together are far apart. If people think the forest is good, for example, forest will lie close to good in the Galileo space. One advantage of this model is that dozens or even hundreds of attitudes and beliefs can be pictured simultaneously in a single picture, which makes it possible to see the interrelationships among the beliefs and attitudes. This in turn is important since changing one attitude or belief often changes others. If forest managers are more aware of such indirect consequences, their management of forests (insofar as this relates to human involvement in the forest) may be improved.

We discuss some of the results of this study below. In essence we are pleased with the method. People (both assessors and local people) seem able to do it, with reasonable amounts of effort. The results generally confirm our previous knowledge of people's views in the area. Data entry and analysis are not onerous.

In recent years, Terra has been developing several relevant new programs built on the idea of "neural networks" (e.g., CatPac ${ }^{\mathrm{TM}}$, Oresme ${ }^{\mathrm{TM}}$,). These represent a type of artificial intelligence, which may allow us to get some of this same information more simply.
One program, called CatPac, can analyze text, in much the same way that the previously mentioned open-ended interviews could be analyzed, to identify frequencies and clustering of concepts which recur within that text. The important difference is that CatPac can do this (once the text is entered) in seconds, whereas the previous methods took days or weeks. With Oresme ${ }^{\mathrm{TM}}$, we can ask it to tell us which concepts are "activated" (as a neuron in our brains would be) when a concept of interest is activated. This allows for an analysis of the way concepts are linked to each other in peoples' minds. Oresme ${ }^{\mathrm{TM}}$ can predict what other concepts will be brought to mind by the mention of any one or more concepts in the study.

A final component in this bundle of software which is of more general interest (beyond assessment per se) is the $\mathrm{ASG}^{\mathrm{TM}}$ (Automatic Strategy Generator) and its predecessor, the $\mathrm{AMG}^{\mathrm{TM}}$ (Automatic Message Generator). These identify which concepts should be emphasized, in an effort at planned change (such as encouraging a "conservation ethic" or encouraging people to consider forests in a more positive light). These concepts can then be used in extension or "advertising" to affect people's views of the forest. Insofar as their views reflect their behavior (Cary and Holmes 1982; Woelfel and Danes 1980; Woelfel et al. 1988a,b; Barnett \& Woelfel forthcoming), such changes could have important impacts on forests.

In our upcoming Cameroon field test, we hope to do brief, open-ended interviews with various stakeholders, and then subject these interviews to CatPac (1991, 1995, Oresme 1991) and ASG (Woelfel 1992) analyses. At the same time, we will be preparing to conduct the Galileo process (described for Kalimantan). We hope then to compare the short (CatPac) version and the longer, more accurate, Galileo version, to see if there are important differences, from the standpoint of assessment. If the CatPac results are as good, or nearly as good as the full fledged Galileo, this approach would be simpler, cheaper, and therefore preferable.

We said at the beginning that we wanted to make assessments of three kinds of conditions (a "conservation ethic", a feeling of proximity to the forest, and a forest-culture link). Although these have been identified as related to sustainable forest management, the exact causal links are not entirely clear. Nor are the values that would indicate the degree to which these conditions apply. One of our goals, as we try these methods in a variety of contexts, is to gain a better understanding of the range of variation (in people's feelings of closeness to the forest, for instance) and how this correlates with forest conditions and forest sustainability. At this point, because we only have a very few cases to compare, we cannot say much about 
specifics like threshold values; but we hope that as we apply these methods in various locales, we can build up a knowledge base which will simplify future assessment tasks.

\section{Results from West Kalimantan}

The most fundamental output of a Galileo is what is called a means matrix. In the means matrix, the mean response (from all the respondents) is computed for every pair of concepts. Put another way, the means matrix reflects the mean distance perceived by the community in question. The program provides extensive descriptive and inferential statistics, including standard deviations, standard errors, indices of skewness and kurtosis, sample size, maximum and minimum values, and other, more global statistics; but for our purposes here, we are satisfied with fairly simple analyses. For these purposes it will suffice to note that the statistical precision of the measures in this study was excellent, with mean distances ranging from about $5 \%$ for the full sample (277 cases $\left.{ }^{6}\right)$ to about $6-9 \%$ within gender segments (about 100 females and 170 males), and from about $10-15 \%$ within each village (roughly 70 cases per village).

One of the strengths of the Galileo is the multitude of ways in which one can look at the data produced. We have selected three ways of analyzing the data.
First we provide perceptual maps or plots for each community, through a gender lens. We then look at the ethnic differences in perception; and we conclude with a discussion of three concepts we view as related to sustainability (good, future, and forest).

\section{Cognitive Maps in Four Communities and for DSWR as a Whole}

Figures 1-5 present the Galileo plots ${ }^{7}$ showing a cognitive map for the total dataset (DSWR, Figure 1), and four maps disaggregated by gender (Figures 2 and 3 ) and by ethnic group (Figures 4 and 5). Although the plots can only represent three of the 20 dimensions in this multidimensional space (much as a photograph only presents us with two of the three dimensions our eyes normally see $)^{8}$, they do provide an appealing visual representation of the (approximate) thinking of a group of people about forests and other natural resources.

Looking at Figure 1, we see the concepts of spirit and fire as rather peripheral. Our reason for including spirit in the list of concepts was not because it came to our minds as a locally appropriate concept in this cognitive domain, but rather because we wanted to examine the DSWR situation (a comparatively sustainable one) in light of the considerable literature on the

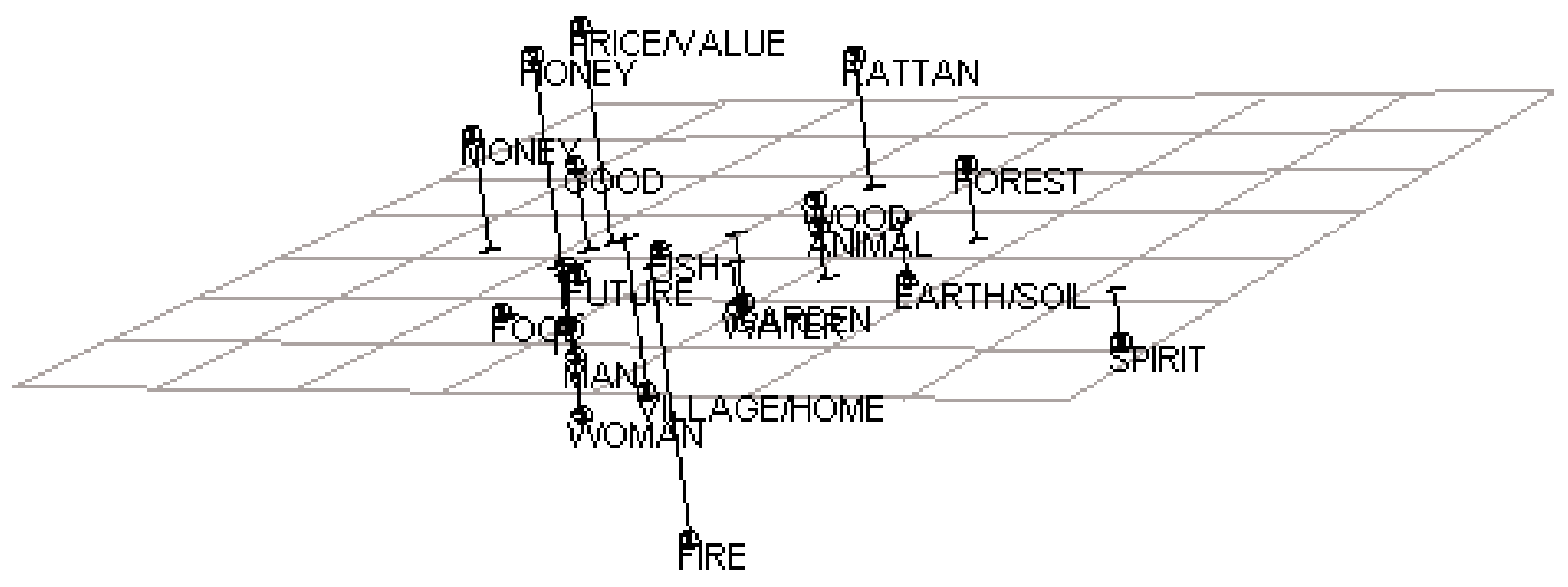

Figure 1. Cognitive Map of DSWR Dataset 


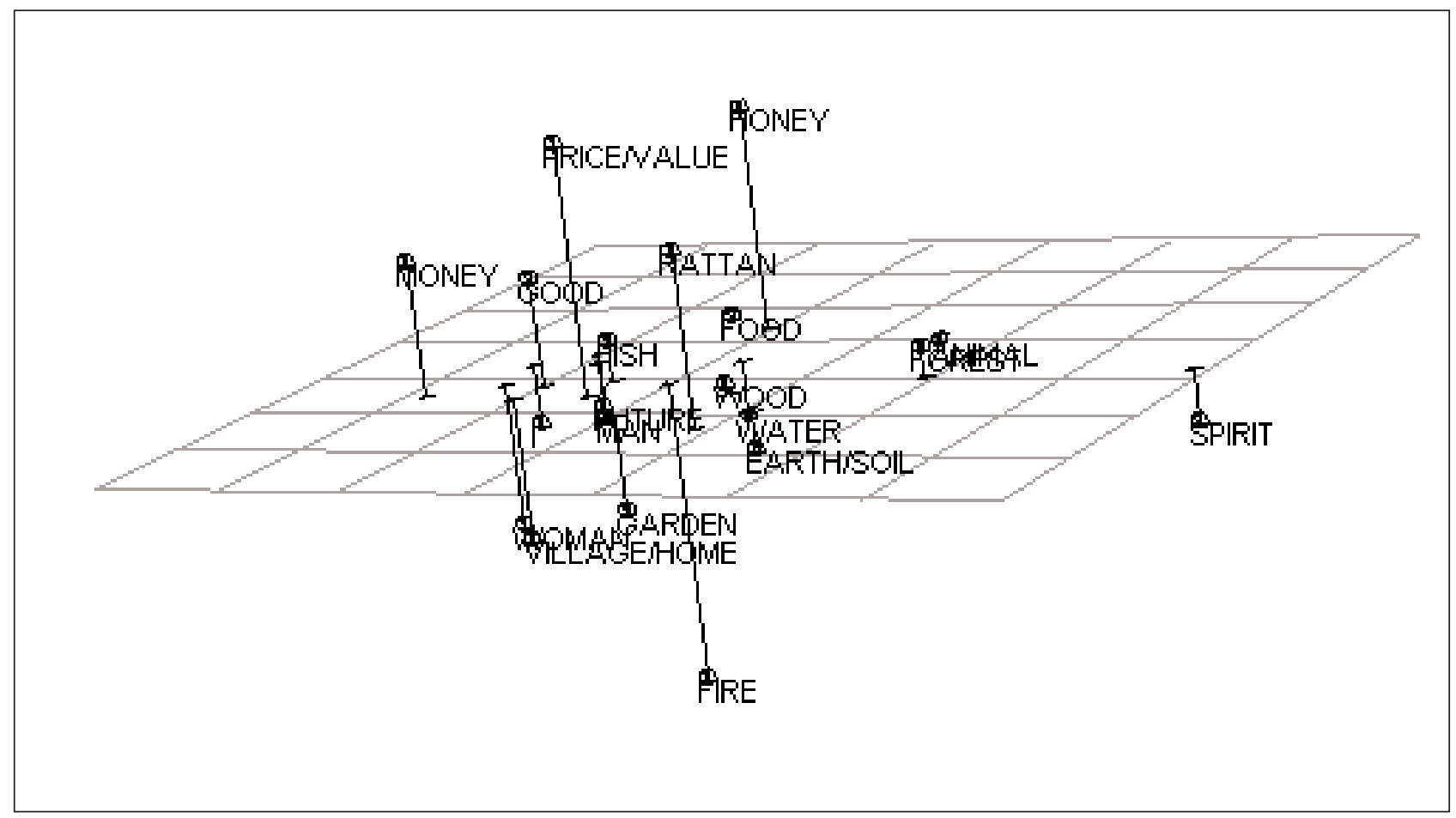

Figure 2. Cognitive Map of Women in DSWR Dataset

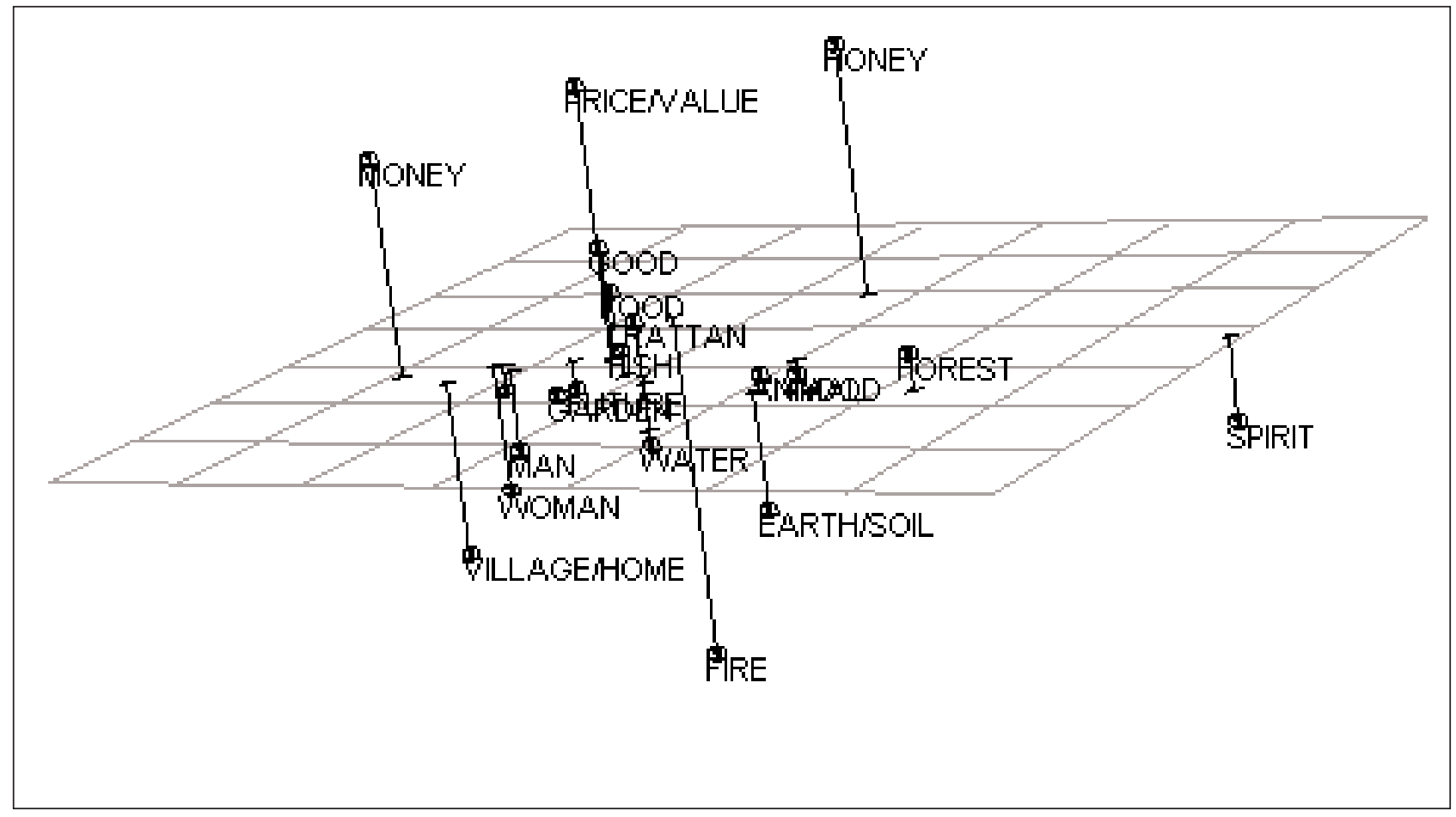

Figure 3. Cognitive Map of Men in DSWR Dataset 


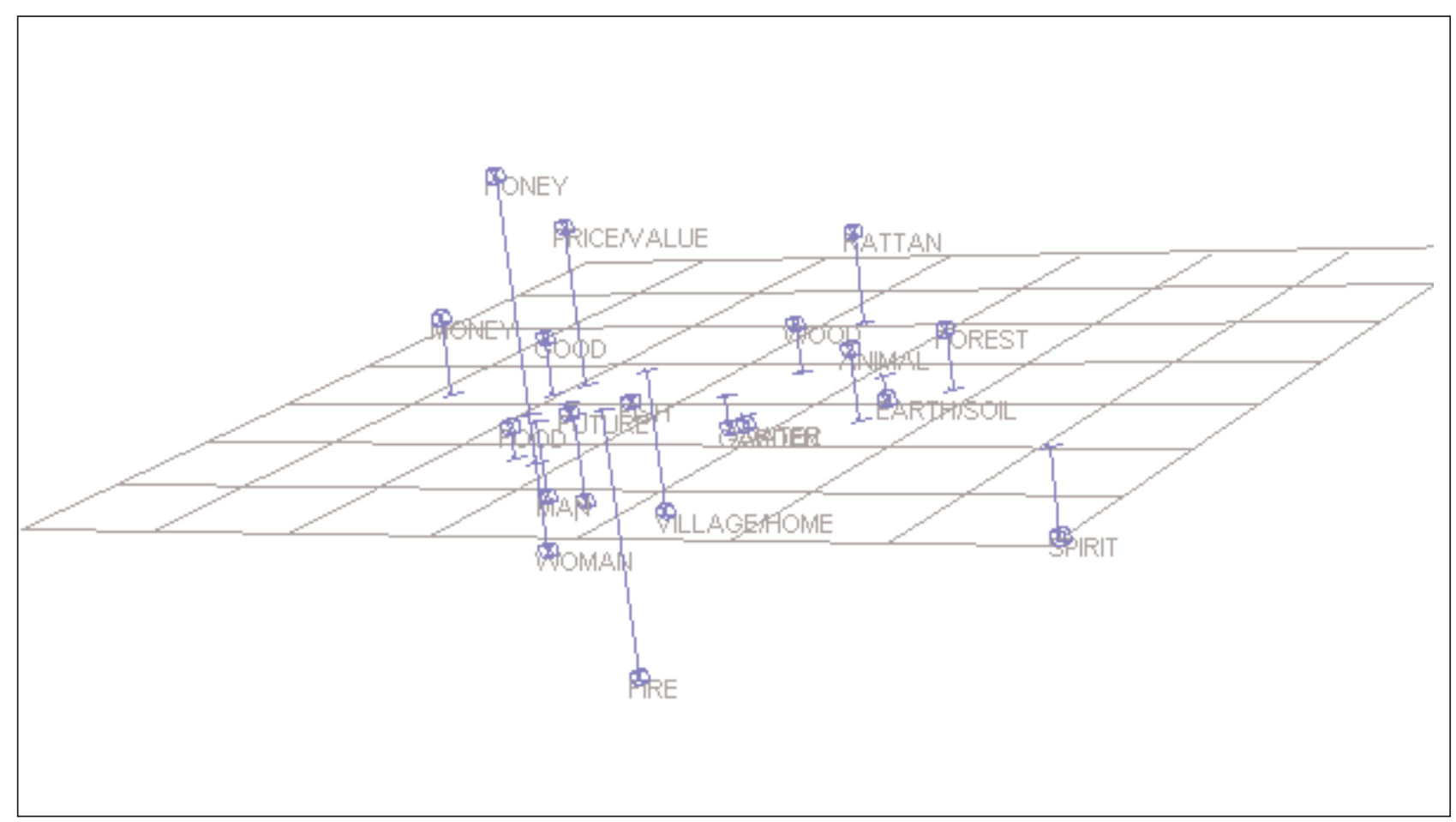

Figure 4. Cognitive Map of Iban in DSWR Dataset

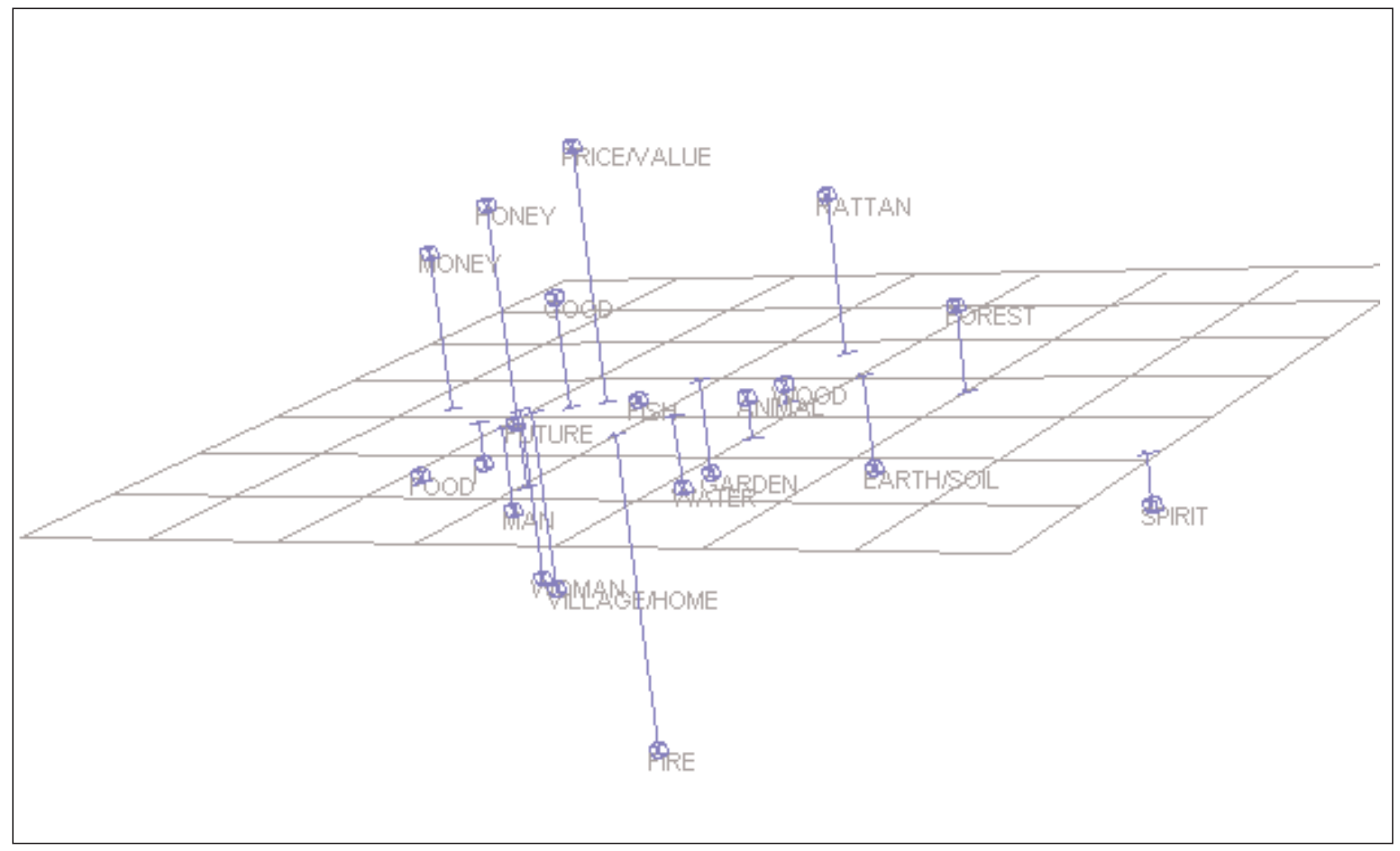

Figure 5. Cognitive Map of Melayu in DSWR Dataset 
close spiritual connection between forest peoples and their environment (e.g., the collections by Banuri and Marglin 1993; Kemf 1993). Others suggest that women are particularly environmentally sensitive (e.g., Diamond and Orenstein 1990; Gomes and Kanner 1995; Roszak 1995). These data do not support such contentions for the West Kalimantan context. Among these people, spirit is the most distant from the other concepts, and it is particularly distant from woman.

We would add however that the terms used for spirit in West Kalimantan are not sufficient to represent all the connotations that go with the English term, "spirituality". Additionally the Iban concept of "spirit" includes both a positive and a negative element; among the Melayu "spirits" seem invariably bad. In fact, there is a wealth of qualitative data suggesting a significant spiritual link, in the western sense, between Bornean peoples and their environment. ${ }^{9}$

Fire, also distant from other concepts, was likewise not a concept that emerged from our knowledge of people's views of the people-forest link in Kalimantan. However, the Conservation Project, with whom we collaborated during data collection, was interested in this issue, since fire is perceived as a significant threat to DSWR's unique the ecosystem. The project wanted to know how people perceived fire in relation to the other concepts we were examining.

Rattan and honey were selected as relevant for both ethnic groups. For the Iban these products are only two of a vast repertoire of regularly gathered non timber forest products; for the Melayu they are the two most important. In the Melayu context, these products have also been the focus of Conservation Project activities to increase production and local incomes. The Kelayang Iban have also long been involved in rattan collection and sale to timber companies and, more recently, processing of handicrafts for sale to the Conservation project. Note the closer distance between honey and money among the Melayu for whom honey collection can constitute a major income source at certain times of the year (Figure 5).

Another interesting feature of these cognitive maps is the fairly uniform closeness with which man and woman are perceived. They are slightly closer among the Iban than among the Melayu, which again fits with our expectations. No matter how we cut the pie, men and women seem to be perceived as much closer than they typically are in American studies of this kind

Table 1. DSWR Men's and Women's Perceptions of the Distance between Forest and Other Study Concepts

\begin{tabular}{lcc}
\hline & All Female & All Male \\
\hline FISH & 3.50 & 3.81 \\
WOOD & 1.75 & 2.17 \\
RATTAN & 2.42 & 2.58 \\
HONEY & 2.96 & 3.24 \\
GARDEN & 4.12 & 3.06 \\
PRICE/VALUE & 6.09 & 5.36 \\
GOOD & 4.22 & 3.94 \\
FUTURE & 4.45 & 4.69 \\
SPIRIT & 4.05 & 4.54 \\
ANIMAL & 2.29 & 2.44 \\
FOOD & 6.48 & 5.10 \\
EARTH/SOIL & 1.65 & 1.72 \\
WATER & 2.78 & 3.10 \\
I & 4.67 & 4.71 \\
MAN & 4.96 & 4.76 \\
WOMAN & 5.85 & 5.21 \\
VILLAGE/HOME & 5.95 & 5.24 \\
FIRE & 6.96 & 5.36 \\
& & \\
\hline
\end{tabular}




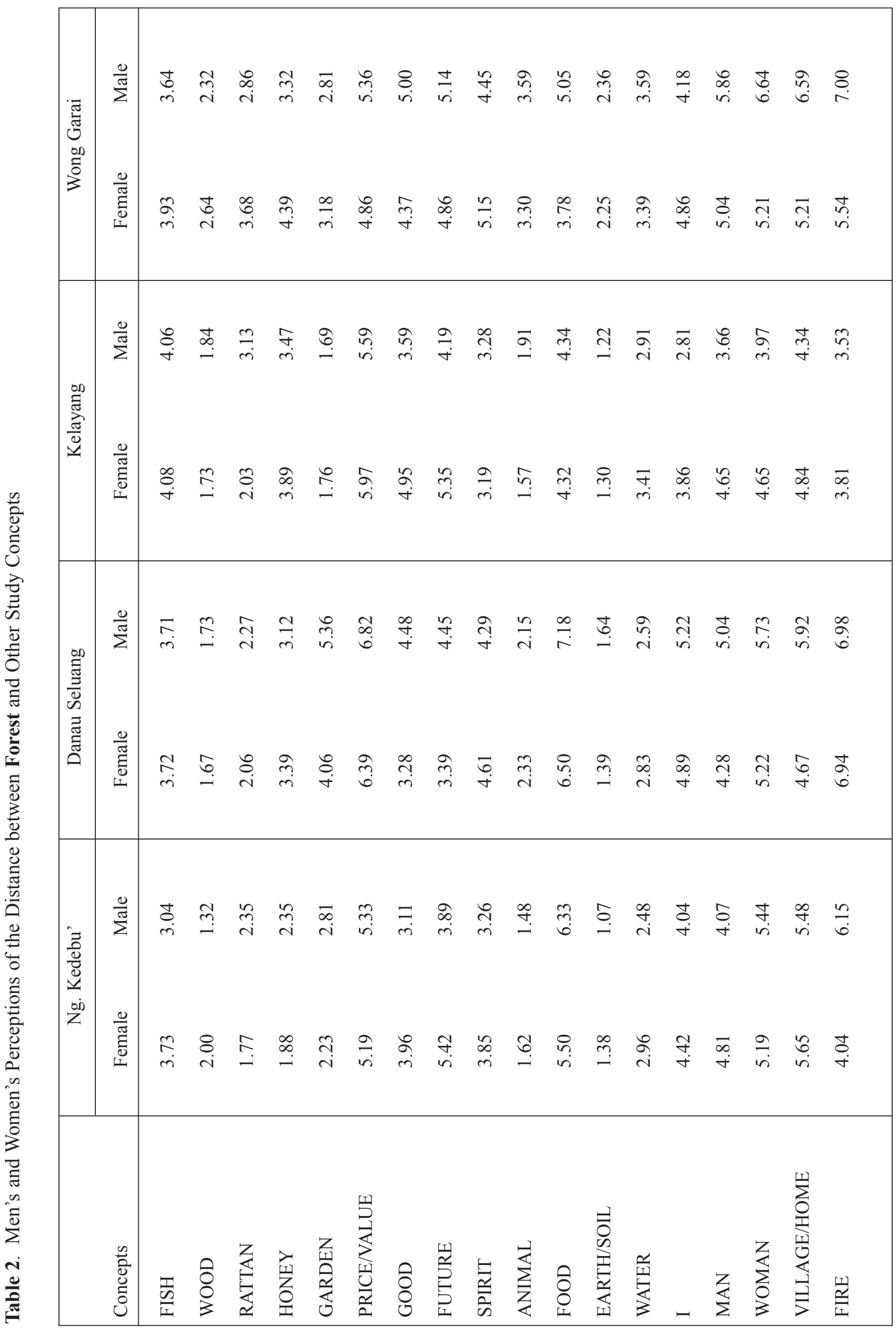


(Newton 1977; Newton, Buck and Woelfel 1984). The comparative lack of gender stereotyping in some Borneo groups has been documented in other studies (see Davison and Sutlive 1991; Dove 1980; Drake 1991; Mashman 1991, for gender studies among Ibanic groups $)^{10}$. Our data seem to support these previous conclusions.

In including the concept, price/value, we were trying to get at the idea of "value" as something abstract and related to values (in a non-economic sense), but the local terms (rega in Melayu and berega' in Iban) always implied both. This is consistent with previous analyses of other Bornean groups (cf. Colfer with Peluso and Chin 1997). Only the Iban analysis (Figure 4) shows this concept to be relatively integrated into the other concepts. This may reflect their higher sociocultural or philosophical valuation of their natural environment than the Melayu, which would be consistent with our impressions as well. The Iban and other Dayaks, though scorned at the national level as "backward", exhibit a marked self-confidence and commitment to their own way of life which does not characterize the Melayu. Although cash is much more important in Melayu daily life, it may be that these Iban, like Kenyah Dayaks, consider money to be of less value than locally produced goods (because money quickly disappears, whereas rice, for instance, can be stored and more easily kept for emergency needs)

Whereas the plots provide the best holistic view of the data, the most accurate reflection of people's estimates of distance is the actual means. Tables 1 and 2 show the distances men and women perceive various concepts to be from one of our central concepts, forest. As mentioned previously, these means are accurate to about $\pm 5 \%$ for the total sample, $\pm 6-8 \%$ for the gender segments, and $\pm 10-15 \%$ within each village. Obviously one could make a very large number of tables and figures, depending on which concepts were of interest for any particular research problem. Table 1 shows results from the total data set (which we call "DSWR"), reflecting the distances estimated by all the respondents in all four communities. Table 2 deals with each of the four villages studied, individually.

For DSWR as a whole, the concepts perceived as closest to forest are earth/soil, wood (predictably), and animals. Rattan, water and honey are also fairly

Table 3. DSWR Men's and Women's Perceptions of the Distance between Money and Other Study Conceps

\begin{tabular}{lcc}
\hline & All Female & All Male \\
\hline FISH & 3.17 & 3.21 \\
WOOD & 4.74 & 3.93 \\
RATTAN & 4.51 & 3.56 \\
HONEY & 3.69 & 3.36 \\
GARDEN & 3.43 & 4.00 \\
PRICE/VALUE & 2.85 & 3.24 \\
GOOD & 3.62 & 3.18 \\
FUTURE & 4.01 & 3.52 \\
SPIRIT & 9.32 & 8.20 \\
ANIMAL & 5.58 & 6.01 \\
FOOD & 3.41 & 4.13 \\
EARTH/SOIL & 5.28 & 4.77 \\
WATER & 5.07 & 4.40 \\
I & 2.22 & 3.29 \\
MAN & 2.75 & 2.89 \\
WOMAN & 2.25 & 2.64 \\
VILLAGE/HOME & 3.46 & 2.99 \\
FIRE & 7.23 & 6.03 \\
& & \\
\hline
\end{tabular}




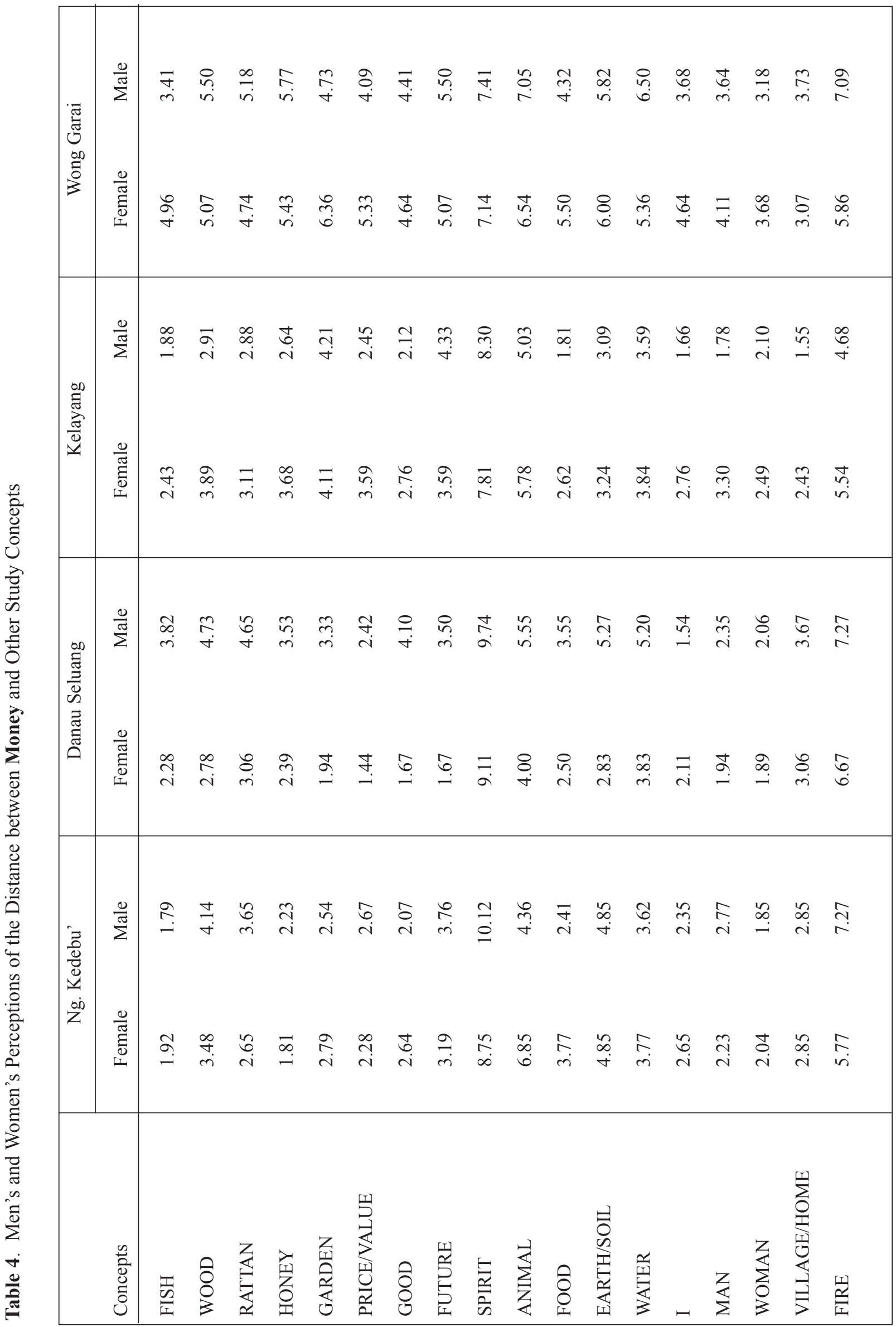


close. Women express the greatest distances between forest and fire, food, and price/value, with men also considering these as comparatively distant from forest. The distance of price/value from forest is interesting in light of international timber prices, and reflects a genuine difference between the views of locals and the views of outsiders. Both men and women consider forest to be closer to man than to woman, though the difference is not great. ${ }^{11}$

Good, future and forest are concepts that we felt bore special significance for sustainability (see below). The distance between forest and these concepts falls in an intermediate range for both men and women. Men consider the forest to be slightly better than women do, and slightly less closely connected with the future. These data do not suggest that these people have a particularly close or positive feeling about the forest, despite their extreme dependence on it, considerable knowledge about it and continual interaction with it ${ }^{12}$. From our general experience we know that forests also contain many dangers (dangerous or poisonous animals, opportunities for injury from falls, fast regrowth into places needed for other uses like housing and agriculture, malevolent spirits, etc.).
The concept, money, provides another lens for looking at perceptions (Tables 3 and 4). In Table 3, it is clear that the people of DSWR consider money to be more tightly integrated into this conceptual domain than is forest. ${ }^{13}$ Women consider money to be closer to people (I, man, woman) than do men. The only concept from which money is truly distant is spirit, and to a lesser extent, fire.

Careful inspection of these tables (1-4) can yield an abundant harvest of insights into the world views found in these four villages, but this brief working paper is not the place to make such a thorough analysis.

\section{Ethnic Differences in Conceptual Distances}

As mentioned before, there are two main ethnic groups in the DSWR area, the Melayu and the Iban. Both groups have lived in the area for a long time, and rely heavily on natural resources for their subsistence, though stereotypically they use very different habitats. The Iban of Wong Garai reflect a habitat use that is closer to the stereotype than do the people of Kelayang, who have more Melayu neighbours and for whom, for

Table 5. DSWR Men's and Women's Perceptions of the Distance between Forest and Other Study Concepts

\begin{tabular}{|c|c|c|c|c|}
\hline & \multicolumn{2}{|c|}{ Iban } & \multicolumn{2}{|c|}{ Melayu } \\
\hline & Forest & Money & Forest & Money \\
\hline FISH & 3.96 & 3.06 & 3.86 & 2.61 \\
\hline WOOD & 2.08 & 4.20 & 1.69 & 3.88 \\
\hline RATTAN & 2.60 & 3.84 & 2.06 & 3.55 \\
\hline HONEY & 3.79 & 4.19 & 2.94 & 2.65 \\
\hline GARDEN & 2.27 & 4.79 & 3.63 & 2.85 \\
\hline PRICE/VALUE & 5.49 & 3.75 & 5.72 & 2.39 \\
\hline GOOD & 4.50 & 3.38 & 4.10 & 2.77 \\
\hline FUTURE & 4.87 & 4.53 & 4.27 & 3.44 \\
\hline SPIRIT & 3.89 & 7.82 & 4.47 & 8.87 \\
\hline ANIMAL & 2.43 & 5.97 & 2.29 & 4.99 \\
\hline FOOD & 4.35 & 3.40 & 6.39 & 3.16 \\
\hline EARTH/SOIL & 1.69 & 4.31 & 1.62 & 4.64 \\
\hline WATER & 3.30 & 4.63 & 2.96 & 4.23 \\
\hline I & 3.89 & 3.10 & 4.93 & 2.19 \\
\hline MAN & 4.70 & 3.18 & 4.95 & 2.42 \\
\hline WOMAN & 4.97 & 2.81 & 5.65 & 2.17 \\
\hline VILLAGE/HOME & 5.14 & 2.60 & 5.46 & 3.21 \\
\hline FIRE & 4.72 & 5.66 & 6.08 & 6.82 \\
\hline
\end{tabular}


instance, fishing is more important than among the Iban of Wong Garai. Similarly, the Melayu of Danau Seluang have more interaction with Iban than do those of $\mathrm{Ng}$. Kedebu'. Previous experience with cognitive mapping in Sumatra (Colfer, Newton and Herman 1989), as well as our qualitative evaluation of differences in values and lifestyles, suggested that ethnic differences might be quite significant.

Table 5 summarizes the overall ethnic differences, using forest and money as key concepts. Considering the differences in the lifestyles of the two groups, there are remarkable similarities, along with some not too surprising differences. ${ }^{14}$ For instance, the Iban live on dry land and practice swidden agriculture. Their agricultural endeavors, represented in English by garden, ${ }^{15}$ are intimately connected with the forest (since forest is regularly cut to make fields; and forest often surround fields). Note the markedly closer connection for the Iban between forest and food.

The Melayu, people who live by fishing in and around the forest, place water slightly closer to forest than do the Iban (who recognize the importance of water for fish and for their agricultural endeavors). Although the Melayu use far fewer forest products generally than do the Iban, they concentrate their forest product collection on three items, wood, rattan and honey. Thus the closer connection between wood and forest, rattan and forest, and honey and forest, for the Melayu, vis-à-vis the Iban.

Not surprisingly the Melayu consider money to be closer, generally, to the other concepts than do the Iban (Table 5). Although both groups use money extensively, the Melayu rely on it for daily life (see also Table 4). Iban men, on the other hand, go away to Malaysia to earn money with which they then buy consumer goods. Iban daily needs are largely supplied by subsistence activities (agroforestry, agriculture, hunting, fishing, etc.). Kelayang ${ }^{16}$ is located closer to Melayu communities than is Wong Garai. It is not surprising that with increasing geographical distance from the Melayu and other marketing outlets, the cognitive distance between money and the other concepts would increase.

\section{Galileo Concepts Related Directly to the Issue of Sustainability}

Having mentioned the concepts, good, future and forest above, as possibly important ones to consider in assessing social C\&I for sustainable forest management,

Table 6. DSWR Cognitive Distances among Selected Concepts for Sustainability.

\begin{tabular}{llll}
\hline & Good & Future & Forest \\
\hline FISH & 3.41 & 5.20 & 3.90 \\
WOOD & 3.73 & 4.97 & 1.86 \\
RATTAN & 3.38 & 4.96 & 2.30 \\
HONEY & 2.96 & 4.93 & 3.32 \\
GARDEN & 3.40 & 4.80 & 3.03 \\
PRICE/VALUE & 3.25 & 4.73 & 5.62 \\
SPIRIT & 7.63 & 7.83 & 4.22 \\
ANIMAL & 5.60 & 5.35 & 2.35 \\
FOOD & 2.97 & 3.82 & 5.49 \\
EARTH/SOIL & 3.64 & 4.03 & 1.65 \\
WATER & 3.56 & 3.86 & 3.11 \\
I & 2.95 & 3.23 & 4.47 \\
MAN & 3.04 & 3.45 & 4.84 \\
WOMAN & 3.16 & 3.83 & 5.35 \\
VILLAGE/HOME & 3.42 & 4.15 & 5.32 \\
FIRE & 5.02 & 5.30 & 5.48 \\
MONEY & 3.04 & 3.92 & 6.26
\end{tabular}




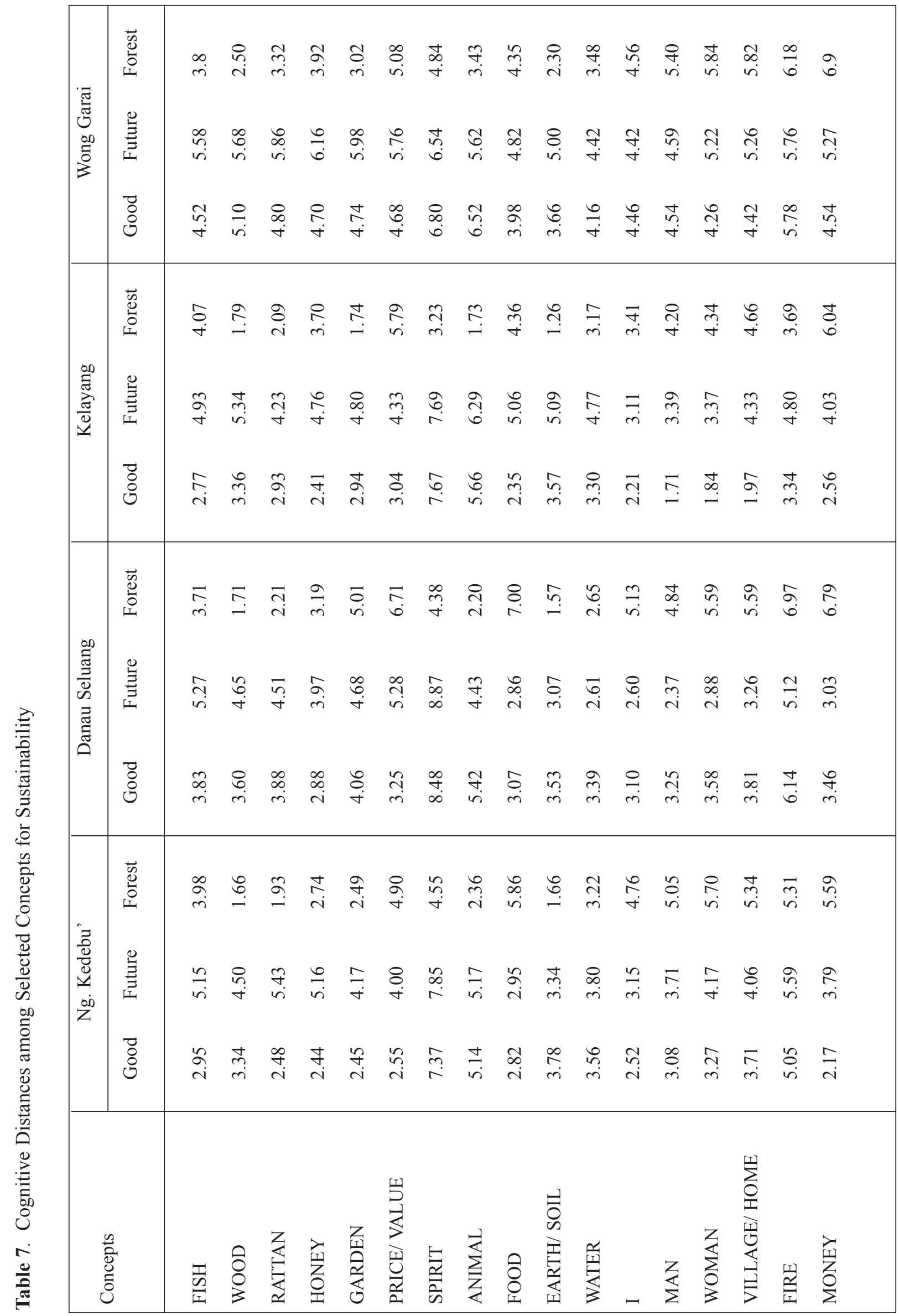


we have prepared two tables (6 and 7) which examine the distances from those concepts to others in the data sets. Table 6 deals with the DSWR data set.

Spirit, interestingly is seen as comparatively close to forest, suggesting a possible mechanism for protecting the forest by encouraging belief in spirits. Iban views of spirits are decidedly ambivalent, including fear; in the Melayu case, spirits are considered to be bad. In Wong Garai, the Iban deal with spirits most safely by exhibiting humility in speech and action. Wanton destruction, boasting of fishing catches, etc. are not done where spirits might see or hear (particularly in the forest). This approach seems to have an obvious relevance for resource use and sustainability.

The distances from price/value and from money to forest are considerably larger than to future, and still larger than that to good. This could suggest the absence of what is considered a "conservation ethic" in the West; though Colfer, Wadley and Harwell have all noted features of the people's world view that suggest a concern about the land and its future capability to produce. ${ }^{17}$ We remain uncertain whether this problem may be with the concept of a "conservation ethic", in the first place. Or perhaps the inclusion of the concepts, "love" and "fear", could provide a useful distance in trying to place different stakeholder groups on some sort of "conservation ethic" continuum.

The small distance between various forest products/production systems (wood, rattan, honey, animals, fish, garden) and forest is in marked distinction from the distance between those products and future. This may reflect a feeling that the future does not lie with exploitation of natural resources, that their future lies elsewhere or with other economic endeavours---despite the comparative proximity of good to these products.

Turning to Table 7 which describes the world view in each village, we find a greater distance between forest and food, for the Melayu as compared to the Iban. The latter obtain virtually all their food from the forest, whereas Melayu food either comes from the lakes and streams or is bought. Woman in all communities is perceived as farther from the forest than is man. ${ }^{18}$

Fire, one of the concepts which was of particular interest to the Conservation Project at DSWR, was fairly far from good and from forest on all sites. This is interesting because of the importance of fire in the Iban system of swidden cultivation; and in fish processing among the Melayu. People who considered fire close to woman or to good, for instance, typically mentioned its role in cooking food. There was considerably more burned forest around Danau Seluang than around Ng. Kedebu'. These data (and qualitative interviews as well) do not support the project's hypothesis that fires were more common in the Danau Seluang area because of different perceptions about fire. Both communities consider fire to be distant from forest and from good--though the people of Ng. Kedebu' see fire and future as more distant than do residents of Danau Seluang (which is near the edge of the reserve, in an area that has been more extensively logged and where losses from fire have been greater).

\section{Conclusions and Recommendations for Future Use}

Although we are pleased with the results of our pretest and plan to revise and continue testing the method elsewhere, some questions have come up in the course of the conduct and analysis of the study.

First, we wonder if, even with a standard 10 unit measuring rod (the "black-white" distance specified for all respondents), the distances will be entirely comparable. Note the higher distances attributed generally in Wong Garai compared to Kelayang (the two Iban communities, see Table 7). We have had a similar experience in East Kalimantan, where we found the people of Long Ampung consistently to estimate higher distances than those in Long Segar (Colfer 1982). Interestingly in that study also the community with the larger distances was also the more remote. This issue has implications for the process of developing threshold values for making comparable cross site assessments. ${ }^{19}$

Second, we suspect we will have to work toward identifying a core set of concepts that are valid or important in all humid tropical forests (or perhaps even in all forests), with empty "slots" in the questionnaire for special, locally determined concepts. However, this will have to be assessed after more studies have been done over the course of the coming year. One of our concerns is the different meanings of a concept in different locations and among different peoples. The different meanings of what we have translated as "garden" between the Iban (umai)and the Melayu (tayak) was already mentioned. Another locally important difference relates to the importance among the Iban of varying stages of forest regrowth (one of which, for instance, kampong, is likely to be much closer to spirit than the concept we selected, babas). A core set, if it could be developed, would simplify the assessment process considerably. Without it, crosssite comparisons become more difficult.

Third, we will need to investigate relevant concepts in a variety of contexts, which lie along a continuum of sustainable forest management from both human and biophysical standpoints. DSWR represents a context in which the forests are and have been fairly sustainably 
managed. We hope to be able to gather comparable data from more diverse stakeholders in Cameroon, Brazil, East Kalimantan, and ideally from temperate forests as well (such as the United States or Europe, see Richardson et al. 1996 or Cary 1995, for related studies). Until we have this range of variation in sustainability, we will not be able to analyze fully the implications of the "conservation ethic", emotional proximity to the forest, and the forest-culture link for sustainability.

In this short paper, we have not attempted a thorough analysis of the data coming from our pre-test. We have rather selected illustrative analyses which we considered possibly useful in assessing the three questions mentioned above. We wanted primarily to examine the method for its cost effectiveness, simplicity and reliability. We found the questionnaires easier for our locally hired collaborators to administer than we anticipated, thus making the cost less than if we had had to do it ourselves. We are satisfied that the results reflect reasonably well the world views of the people, as determined by Colfer's, Wadley's, and Harwell's previous experience there. We feel there remains room for refinement, on the issue of a "conservation ethic".

As mentioned earlier, we would like to make the process still simpler and less expensive if we can do so without excessively sacrificing reliability. We remain uncertain what kinds of responses we will get among populations living in contexts marked by different level of sustainability. This information we can only get by further literature searches and by continued testing, as currently planned.

\section{END NOTES}

1. Colfer is a Principal Scientist at CIFOR and Social Science Coordinator for the project "Assessing Sustainable Forest Management: Testing Criteria and Indicators." She lived at the research site for 15 months in 1992-93. Joseph Woelfel is Professor of Communication at the University at Buffalo, in New York, and the principal originator of the Galileo methods discussed in this paper. Reed L. Wadley is a doctoral candidate in anthropology at Arizona State University, who did more than two years of fieldwork in Wong Garai (1992-1994). Emily Harwell is a doctoral candidate at Yale University's School of Forestry and Environmental Studies, doing long term research in Kelayang, West Kalimantan. Galileo, CatPac, Oresme, and ASG are copyrights of The Galileo Company. TerraVision is copyright J. K Woelfel, J. D. Woelfel and S. Danielsen.

2. These tests were part of a CIFOR project entitled "Assessing Sustainable Forest Management: Testing Criteria and Indicators", led by Dr. Ravi Prabhu. The particular activities reported in this paper were undertaken with sponsorship from USAID, and in collaboration with the Indonesian Government (PHPA), Wetlands International - Indonesia Programme, and with the informal cooperation of the ODA Sustainable Forest Management Project in West Kalimantan. We thank all these institutions for their substantive contributions and cooperation in all our efforts. Most importantly, we thank the people of the Danau Sentarum Wildlife Reserve and its surroundings, for their patience and kindness in answering our many questions.

3. Traditionally, a Galileo study requires respondents to report their perceptions of the differences (often called "distances") among a set of concepts which are central to the definition of some topic, e.g., forests. These estimated dissimilarities are averaged across all respondents in any segment and projected onto orthogonal coordinate axes to produce a perceptual map or space. Within this space, distances are predictive of attitudes, beliefs and behaviors. Technically, 277 respondents estimated the pairwise dissimilarities among a set of terms including forest and 19 other concepts identified in previous analyses as pertinent to the perception of forests in Kalimantan villages. The resulting square mean dissimilarities matrix was then analyzed in a number of ways, including perceptual maps (multidimensional scaling or MDS), charts, graphs, tables and advanced artificial neural networks (ANN's). Perceptual maps were made using Galileo ${ }^{\mathrm{TM}}$ software, which produces very precise representations of the dissimilarities in graphic form, and which allows transformations (rotations and translations) to common orientations for easy comparisons of data over time and across subsamples. Previous research has shown Galileo to be an appropriate model when 
holistic models of cognitive structure and processes are required, when precise results are desirable, when a standard metric needs to be maintained across time or subsamples, as when time-ordered maps are needed, or when maps are to be compared from sample to sample, and when the concepts to be mapped are known. Galileo modeling may be less appropriate when investigators are uncertain as to what concepts occur in the cognitive model, or when light respondent burdens are crucial, there is no need to maintain an invariant metric over time and across samples, and precise results are not important (Woelfel \& Barnett 1982; Woelfel et al., 1986; Cary et al., 1989; Woelfel et al., 1989; Woelfel \& Barnett 1992). When less is known about the concepts that need to be included, as is the case in preliminary studies, similar results can be obtained from CatPac, a self-organizing neural network which reads text and uncovers the main underlying concepts. CatPAacmakes it possible to work from in-depth interviews rather than quantitative scales and derive similar results (Cary, 1995).

4. CatPac (described below) is a computer program which can perform this function quickly and easily from text.

5. Version 3.0, Terra Research \& Computing Co., 1995.

6. Sample sizes are given approximately because overall sample size varies slightly from item to item. Complete statistics are available from the authors.

7. Plots were made with TerraVision ${ }^{\mathrm{TM}}$, an interactive computer graphics program for perceptual mapping. (Terra Research \& Computing 1995).

8. In this case, the probability that the concept will be in its correct position vis-à-vis other concepts on the map is roughly $75 \%$---a high figure, because of the high degree of agreement among respondents at DSWR about the distances among concepts.

9. cf. Davison and Sutlive 1993; Howell 1984; Roseman 1991; Colfer, with Peluso and Chin 1997; observations during the June fieldwork of Iban ceremonies that "feed the spirits", as part of the rice growing agricultural cycle; and more.

10. See Colfer 1981, 1982, 1983, 1985a, 1985b, 1991, on the Kenyah; Sutlive and Appell, eds. 1991, for a thorough coverage of the issue; or Tsing 1993, for an unusual approach.
11. Colfer found similar results among the Kenyah of two locations in East Kalimantan in 1980 (Colfer 1982).

12.In the 1980 study of perceptions of forests in East Kalimantan, forest and good were considered quite close among both adults and young people in the remote Long Ampung; a little more distant among adults in Long Segar (a resettlement village closer to "civilization"), and still more distant among Long Segar's young people (Colfer 1982).

13. Table 6 shows the substantial distance between forest and money. That forest and money are not compared on this table is an artifact of our analysis process. We also conducted an analysis which used these results to predict the outcome of a vote where people had to choose between money and forest. Money won by a landslide.

14. In the Sumatra case mentioned above, one ethnic group was indigenous and one in-migrants from a very different environment and culture.

15. 'Garden" is not a good translation for umai, the Iban word used in the form. However, because the two groups have such different kinds of agriculture, and we wanted to compare the findings, we have used one English translation. Umai would be more properly defined as "field".

16. Pseudonyms are used for individual villages, in order to protect their privacy.

17. Wadley notes that Wong Garai men make considerable money logging in Sarawak, and suggests, based on these data, that the forests at home may be considered more valuable as they are than are forests elsewhere.

18.This was also true in the 1980 East Kalimantan study mentioned above (Colfer 1982). From simple interest, we performed an Automatic Message Generator (AMG) analysis on these data, for possible use in extension or awareness programs to encourage people to use the forest more sustainably. This software identifies the concepts with the most potential for moving forest closer to me. These concepts are located between forest and me in the cognitive space. The two top contenders were three-concept messages, consisting of fish, honey, and woman; and honey. woman, and village/home. A message which links forest to these concepts is likely to result 
in local people's feeling closer to the forest and, presumably, behaving more sustainably towards it. Either of these 3-concept combinations had the potential to remove all but $5 \%$ of the distance remaining between forest and me.

19. One common practice of Galileo researchers which might alleviate this difficulty is to choose two concepts from within the domain as the criterion pair. Several researchers (Woelfel \& Fink 1980) have suggested that this might provide a more accurate model, since the measuring rod does not have to be "transported" such large psychological distance in order to be compared with the distances in the domain. A second advantage is that the internal criterion distance can be used to rescale the data after the fact, should differences in scale size appear.

\section{Bibliography}

Banuri. T and F. A. Marglin (eds.), 1993. Who will Save the Forests: Knowledge Power and Environmental Destruction. London: Zed Books.

Barnett, G. and J. Woelfel, forthcoming. (Editors and Contributors), Readings in the Galileo System: Theory, Methods and Applications, Dubuque, Iowa: Kendall-Hunt, 1988.

Cary, J. W. and W. E. Holmes, 1982. Relationships among Farmers' Goals and Farm Adjustment Strategies: Some Empirics of a Multidimensional Approach. The Australian Journal of Agricultural Economics (August), pp. 114-130.

Cary, John, 1995. An Analysis of Perceptions of High country Landscapes: A Test of Comparative Quantitative Methods and an Artificial Neural Network Technique. Report of results from a pilot study for Manaaki Whenua Landcare Research New Zealand, Ltd. (May).

Cary, J. W., A. W. Kenelly and R. C. Bell, 1989. A Comparison of Methods for Tracking Consumer Perceptions of Meat. Parkville, Victoria, Australia: School of Agriculture and Forestry and Department of Psychology.

CatPac 4 Windows: a self-organizing neural network for the analysis of text, 1995. Terra, Birmingham, MI, (w. J.K. Woelfel and S. Danielsen).

CatPac: a self-organizing neural network for the analysis of text, 1991. Terra, Birmingham, MI, (w. J.K. Woelfel and Scott Danielsen).

Colfer, Carol J. Pierce, 1981. Women, Men and Time in the Forests of Kalimantan. Borneo Research Bulletin 13(2):75-85. (also Environment and Policy Institute Reprint No. 25, 1982).

Colfer, Carol J. Pierce, 1982. Women of the Forest: An Indonesian Example. In Women in Natural Resources: An International Perspective. Stock, Force and Ehrenreich (eds.). Moscow, Idaho: University of Idaho Press.

Colfer, Carol J. Pierce, 1983. Change and Indigenous Agroforestry in East Kalimantan. Borneo Research Bulletin 15(1\&2):3-20, 70-86 (partially reproduced in Whose Trees?: Proprietary Dimensions of Forestry, edited by Fortmann and Bruce, Boulder, Colorado: Westview Press, 1987:306-309).

Colfer, Carol J. Pierce, 1985a. On Circular Migration: From the Distaff Side. Labour Circulation and the Labour Process (G. Standing, ed.). Geneva: Croom Helm Ltd.

Colfer, Carol J. Pierce, 1985b. Female Status and Action in Two Dayak Communities. Women in Asia and the Pacific: Toward an East-West Dialogue (M. Goodman, ed.). Honolulu: University of Hawaii Press.

Colfer, Carol J. Pierce, 1991. Indigenous Rice Production and the Subtleties of Culture Change. Agriculture and Human Values VIII $(1,2): 67-84$.

Colfer, Carol J. Pierce, Barbara Newton, and Herman, 1989. Ethnicity: An Important Consideration in Indonesian Agriculture. Agriculture and Human Values VI(3):52-67.

Colfer Carol J.Pierce, Nancy Peluso and Chin Sec Chung (1977). Beyond Slash and Burn: Lessons from the Kenyah in managing Borneo's Rain Forests. New York: New York Botanical Gardens.

Davison, Julian and Vinson Sutlive, 1991. The Children of Nising: Images of Headhunting and Male Sexuality in Iban Ritual and Oral Literature. In Female and Male in Borneo: Contributions and Challenges to Gender Studies. (Sutlive and Appell, eds.) Williamsburg, Virginia: Borneo Research Council (Monograph Series, No. 1), pp.153-230.

Diamond, Irene and Gloria Orenstein (eds.), 1990. Reweaving the World: The Emergence of Ecofeminism. San Francisco: Sierra Club Books. 
Drake, Richard Allen, 1991. The Cultural Logic of Textile Weaving Practices Among the Ibanic People. In Female and Male in Borneo: Contributions and Challenges to Gender Studies. (Sutlive and Appell, eds.) Williamsburg, Virginia: Borneo Research Council (Monograph Series, No. 1), pp. 271-294.

Foldy, J., and J. Woelfel,1992. "Cognitive Processes as Damped Harmonic Oscillators, Quality and Quantity. GALILEO: an integrated system for the analysis of cognitive processes (contains 18 programs in $5.5 \mathrm{mb}$ ), 1991. Terra, Birmingham (J. Woelfel and Scott Danielsen).

Gomes, Mary E. and Allen D. Kanner, 1995. The Rape of the Well-Maidens: Feminist Psychology and the Environmental Crisis. In Ecopsychology (Theodore Roszak, Mary E. Gomes and Allen D. Kanner, eds.). San Francisco: Sierra Club Books, pp. 111-121.

Howell, Signe, 1984. Society and Cosmos Chewong of Peninsular Malaysia. Chicago: University of Chicago Press.

Kemp, Elizabeth, ed., 1993. The Law of the Mother: Protecting Indigenous Peoples in Protected Areas. San Francisco: Sierra Club Books.

Mashman, Valerie, 1991. Warriors and Weavers: A Study of Gender Relations Among the Iban of Sarawak. In Female and Male in Borneo: Contributions and Challenges to Gender studies. (Sutlive and Appell, eds.) Williamsburg, Virginia: Borneo Research Council (Monograph Series, No. 1), pp. 231-270.

Newton, B., 1977. Perceptions of Sex Roles at the University of Hawaii. Paper presented at Women in Communication Convention. Honolulu, Hawaii (October).

Newton, B., E. Buck and J. Woelfel, 1984. Metric multidimensional scaling of viewer's perceptions of TV in five countries, Human Organization.

ORESME: a self-organizing neural network for non-hierarchical classification, 1991. Terra, Birmingham, MI, (J. K. Woelfel and Scott Danielsen).

Richardson, Catherine Woods, Robert G. Lee and Marc L. Miller, 1996. Thinking about Ecology: Cognition of Pacific Northwest Forest Managers across Diverse Institutions. Human Organization 55(3):314-323.

Roseman, Marina,1991. Healing Sounds from the Malaysian Rainforest. Berkeley: University of California Press.

Roszak, Betty, 1995. The Spirit of the Goddess. In Ecopsychology (Theodore Roszak, Mary E. Gomes and Allen D. Kanner, eds.) San Francisco: Sierra Club Books, pp. 288-300.

Sutlive, Vinson H. and George N. Appell, eds., 1991. Female and Male in Borneo: Contributions and Challenges to Gender Studies. Williamsburg, Virginia: Borneo Research Council (Monograph Series No. 1).

TerraVision: a 3-dimensional interactive display system for perceptual maps, 1995. Terra, Birmingham, MI (w. J.K. Woelfel and S. Danielsen).

Tsing, Anna Lowenhaupt, 1993. In the Realm of the Diamond Queen. Princeton: Princeton University Press.

Woelfel, J. and Edward L. Fink (1980). The Measurement of Communication Processes: Galileo Theory and Method. Academic Press,New York.

Woelfel, J. and J. Danes, 1980. Multidimensional Scaling Models for Communication Research. In Multivariate Techniques in Communication Research, P. Monge and J. Capella (Eds),Academic Press, New York, pp. 333 - 364.

Woelfel, J., M. Cody, J. Gillham, and R. Holmes, 1980. Basic Premises of Multidimensional Attitude Change Theory. Human Communication Research, Winter, pp. 153-167

Woelfel, J., and G. Barnett, 1982. Multidimensional Scaling in Riemann Space. Quality and Quantity 16: 461491.

Woelfel, J., D. L. Kincaid, B. Newton and J. Lee, 1986. The Effect of Compound Messages on the Global Characteristics of Galileo Spaces. Quality and Quantity, 20: 133-145.

Woelfel, J., R. Holmes, M. Cody and E. Fink, 1988a. A Multidimensional Scaling Based Procedure for Designing Persuasive Messages and Measuring Their Effects. In Readings in the Galileo System: Theory, Methods and Applications, G. A. Barnett and J. Woelfel, Dubuque, Iowa, Kendall-Hunt, pp. 235-242.

Woelfel, J., R. A. Holmes, B. Newton and D. L. Kincaid, 1988b. An Experimental Measure of the Mass of Occupation Names. In Readings in the Galileo System: Theory, Methods and Applications, G. A. Barnett and J. Woelfel, Dubuque, Iowa, Kendall-Hunt, pp. 313-332.

Woelfel, J., G. A. Barnett and R. Pruzek, 1989. Rotation to Simple Processes: The effect of Alternative Rotation Rules on Observed Patterns in Time-ordered Measurements. Quality and Quantity, 23:3-20.

Woelfel, J., and G. A. Barnett, 1992. Procedures for Controlling Reference Frame Effects in the Measurement of Multidimensional Processes. Quality and Quantity 26: 367-381. 


\title{
Appendix A - Typical Galileo Questionnaire, Using the Concepts from DSWR
}

\author{
Instructions
}

Please estimate how different or "far apart" each of the following words or phrases is from each of the others. The more different, or further apart they seem to be, the larger the number you should write. To help you know what size number to write, remember black and white are 10 units apart.

If two words or phrases are not different at all, please write zero (0). If you have no idea, just leave the space blank.

Thank you very much for your help.

\begin{tabular}{|c|c|c|c|}
\hline \multicolumn{4}{|c|}{ black and white } \\
\hline \multicolumn{4}{|c|}{ COL. - ----- } \\
\hline 0102 & $9-17$ & FISH & and WOOD \\
\hline 0103 & $18-26$ & FISH & and RATTAN \\
\hline 0104 & $27-35$ & FISH & and HONEY \\
\hline 0105 & $36-44$ & FISH & and GARDEN \\
\hline 0106 & $45-53$ & FISH & and PRICE/VALUE \\
\hline 0107 & $54-62$ & FISH & and GOOD \\
\hline 0108 & $63-71$ & FISH & and FUTURE \\
\hline 0109 & $72-80$ & FISH & and SPIRIT \\
\hline \multicolumn{4}{|c|}{ black and white } \\
\hline \multicolumn{4}{|c|}{ 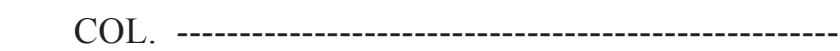 } \\
\hline 0110 & $9-17$ & FISH & and ANIMAL \\
\hline 0111 & $18-26$ & FISH & and FOOD \\
\hline 0112 & $27-35$ & FISH & and FOREST \\
\hline 0113 & $36-44$ & FISH & and EARTH/SOIL \\
\hline 0114 & $45-53$ & FISH & and WATER \\
\hline 0115 & $54-62$ & FISH & and I \\
\hline 0116 & $63-71$ & FISH & and MAN \\
\hline 0117 & $72-80$ & FISH & and WOMAN \\
\hline \multicolumn{4}{|c|}{ black and white } \\
\hline \multicolumn{4}{|c|}{ 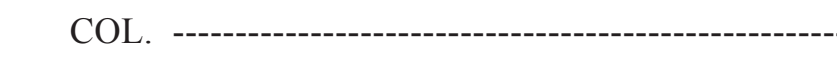 } \\
\hline 0118 & $9-17$ & FISH & and VILLAGE/HOME \\
\hline 0119 & $18-26$ & FISH & and FIRE \\
\hline 0120 & $27-35$ & FISH & and MONEY \\
\hline 0203 & $36-44$ & WOOD & and RATTAN \\
\hline 0204 & $45-53$ & WOOD & and HONEY \\
\hline 0205 & $54-62$ & WOOD & and GARDEN \\
\hline 0206 & $63-71$ & WOOD & and PRICE/VALUE \\
\hline 0207 & $72-80$ & WOOD & and GOOD \\
\hline
\end{tabular}


black and white

\begin{tabular}{|c|c|c|c|}
\hline \\
\hline 0208 & $9-17$ & WOOD & and FUTURE \\
\hline 0209 & $18-26$ & WOOD & and SPIRIT \\
\hline 0210 & $27-35$ & WOOD & and ANIMAL \\
\hline 0211 & $36-44$ & WOOD & and FOOD \\
\hline 0212 & $45-53$ & WOOD & and FOREST \\
\hline 0213 & $54-62$ & WOOD & and EARTH/SOIL \\
\hline 0214 & $63-71$ & WOOD & and WATER \\
\hline 0215 & $72-80$ & WOOD & and I \\
\hline \multicolumn{4}{|c|}{ black and white } \\
\hline \multicolumn{3}{|c|}{ 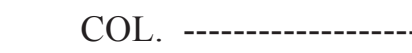 } & and MAN \\
\hline $\begin{array}{l}0216 \\
0217\end{array}$ & $\begin{array}{c}9-17 \\
18-26\end{array}$ & $\begin{array}{l}\text { WOOD } \\
\text { WOOD }\end{array}$ & $\begin{array}{l}\text { and MAN } \\
\text { and WOMAN }\end{array}$ \\
\hline 0218 & $27-35$ & WOOD & and VILLAGE/HOME \\
\hline 0219 & $36-44$ & WOOD & and FIRE \\
\hline 0220 & $45-53$ & WOOD & and MONEY \\
\hline 0304 & $54-62$ & RATTAN & and HONEY \\
\hline 0305 & $63-71$ & RATTAN & and GARDEN \\
\hline 0306 & $72-80$ & RATTAN & and PRICE/VALUE \\
\hline
\end{tabular}

black and white

\begin{tabular}{|c|c|c|c|}
\hline 0307 & $9-17$ & RATTAN & \multirow{2}{*}{$\begin{array}{l}\text { and GOOD } \\
\text { and FUTURE }\end{array}$} \\
\hline 0308 & $18-26$ & RATTAN & \\
\hline 0309 & $27-35$ & RATTAN & and SPIRIT \\
\hline 0310 & $36-44$ & RATTAN & and ANIMAL \\
\hline 0311 & $45-53$ & RATTAN & and FOOD \\
\hline 0312 & $54-62$ & RATTAN & and FOREST \\
\hline 0313 & $63-71$ & RATTAN & and EARTH/SOIL \\
\hline \multirow[t]{3}{*}{0314} & $72-80$ & RATTAN & and WATER \\
\hline & \multicolumn{2}{|c|}{ black and white } & \\
\hline & \multicolumn{2}{|c|}{ COL. ---------------. } & \\
\hline 0315 & $9-17$ & RATTAN & and I \\
\hline 0316 & $18-26$ & RATTAN & and MAN \\
\hline 0317 & $27-35$ & RATTAN & and WOMAN \\
\hline 0318 & $36-44$ & RATTAN & and VILLAGE/HOME \\
\hline 0319 & $45-53$ & RATTAN & and FIRE \\
\hline 0320 & $54-62$ & RATTAN & and MONEY \\
\hline 0405 & $63-71$ & HONEY & and GARDEN \\
\hline 0406 & $72-80$ & HONEY & and PRICE/VALUE \\
\hline
\end{tabular}


black and white

COL.

0407 9-17 HONEY

0408 18-26 HONEY

0409 27-35 HONEY

0410 36-44 HONEY

0411 45-53 HONEY

0412 54-62 HONEY

0413 63-71 HONEY

and GOOD

0414 72-80 HONEY

and FUTURE

and SPIRIT

and ANIMAL

and FOOD

and FOREST

and EARTH/SOIL

and WATER

black and white

COL.

0415 9-17 HONEY

0416 18-26 HONEY

0417 27-35 HONEY

0418 36-44 HONEY

0419 45-53 HONEY

0420 54-62 HONEY

0506 63-71 GARDEN

0507 72-80 GARDEN

and I

and MAN

and WOMAN

and VILLAGE/HOME

and FIRE

and MONEY

and PRICE/VALUE

and GOOD

black and white

COL.

0508 9-17 GARDEN

0509 18-26 GARDEN

0510 27-35 GARDEN

0511 36-44 GARDEN

0512 45-53 GARDEN

0513 54-62 GARDEN

0514 63-71 GARDEN

0515 72-80 GARDEN

and FUTURE

and SPIRIT

and ANIMAL

and FOOD

and FOREST

and EARTH/SOIL

and WATER

and I

black and white

COL.

0516 9-17 GARDEN

0517 18-26 GARDEN

0518 27-35 GARDEN

0519 36-44 GARDEN

0520 45-53 GARDEN

0607 54-62 PRICE/VALUE

0608 63-71 PRICE/VALUE

0609 72-80 PRICE/VALUE

and MAN

and WOMAN

and VILLAGE/HOME

and FIRE

and MONEY

and GOOD

and FUTURE

and SPIRIT

black and white

COL.

0610 9-17 PRICE/VALUE

0611 18-26 PRICE/VALUE

0612 27-35 PRICE/VALUE

0613 36-44 PRICE/VALUE

0614 45-53 PRICE/VALUE

0615 54-62 PRICE/VALUE

0616 63-71 PRICE/VALUE

0617 72-80 PRICE/VALUE

and ANIMAL

and FOOD

and FOREST

and EARTH/SOIL

and WATER

and I

and MAN

and WOMAN 
black and white

COL.

\begin{tabular}{llll}
0618 & $9-17$ & PRICE/VALUE & \multicolumn{1}{c}{ and VILLAGE/HOME } \\
0619 & $18-26$ & PRICE/VALUE & and FIRE \\
0620 & $27-35$ & PRICE/VALUE & and MONEY \\
0708 & $36-44$ & GOOD & and FUTURE \\
0709 & $45-53$ & GOOD & and SPIRIT \\
0710 & $54-62$ & GOOD & and ANIMAL \\
0711 & $63-71$ & GOOD & and FOOD \\
0712 & $72-80$ & GOOD & and FOREST \\
\multicolumn{3}{c}{ black and white } &
\end{tabular}

$\begin{array}{ccc}0713 & 9-17 \text { GOOD } & \text { and EARTH/SOIL } \\ 0714 & 18-26 \text { GOOD } & \text { and WATER } \\ 0715 & 27-35 \text { GOOD } & \text { and I } \\ 0716 & 36-44 \text { GOOD } & \text { and MAN } \\ 0717 & 45-53 \text { GOOD } & \text { and WOMAN } \\ 0718 & 54-62 \text { GOOD } & \text { and VILLAGE/HOME } \\ 0719 & 63-71 \text { GOOD } & \text { and FIRE } \\ 0720 & 72-80 \text { GOOD } & \text { and MONEY } \\ & \text { black and white } & \end{array}$

$\begin{array}{cccc}0809 & 9-17 & \text { FUTURE } & \text { and SPIRIT } \\ 0810 & 18-26 & \text { FUTURE } & \text { and ANIMAL } \\ 0811 & 27-35 & \text { FUTURE } & \text { and FOOD } \\ 0812 & 36-44 & \text { FUTURE } & \text { and FOREST } \\ 0813 & 45-53 & \text { FUTURE } & \text { and EARTH/SOIL } \\ 0814 & 54-62 & \text { FUTURE } & \text { and WATER } \\ 0815 & 63-71 & \text { FUTURE } & \text { and I } \\ 0816 & 72-80 & \text { FUTURE } & \text { and MAN } \\ & \text { black and white }\end{array}$

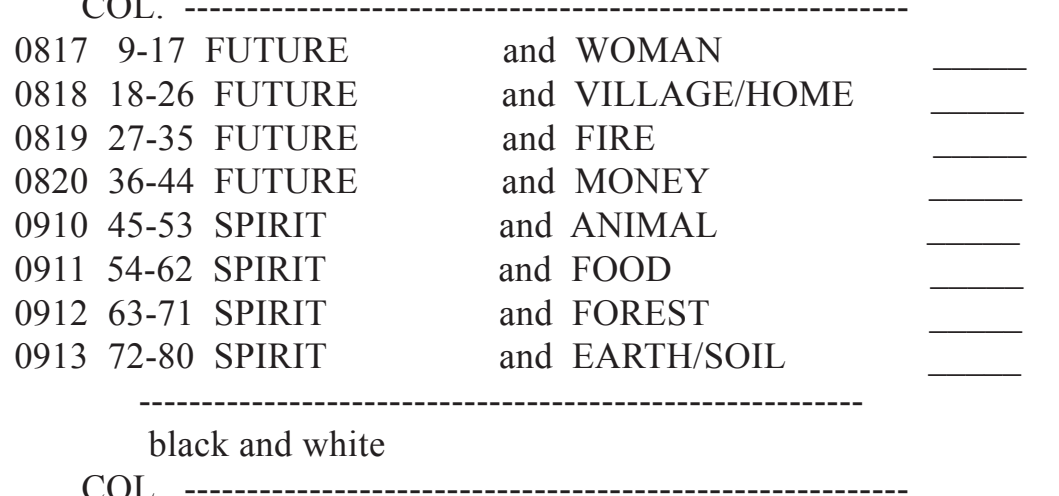

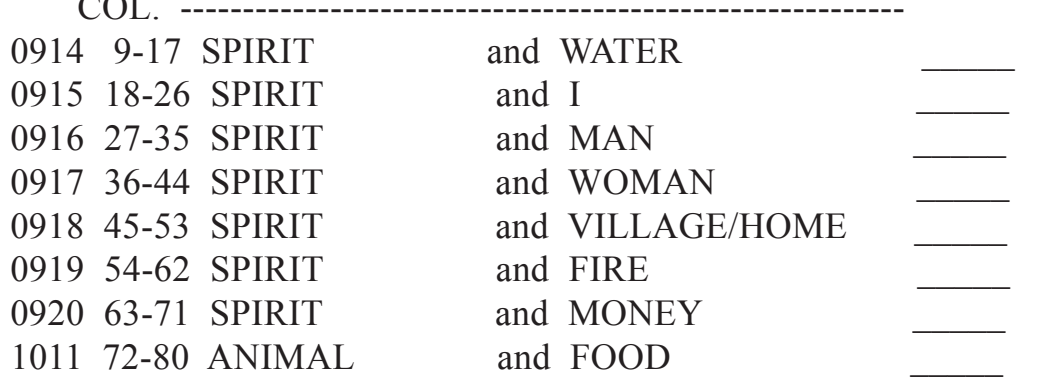


black and white

COL.

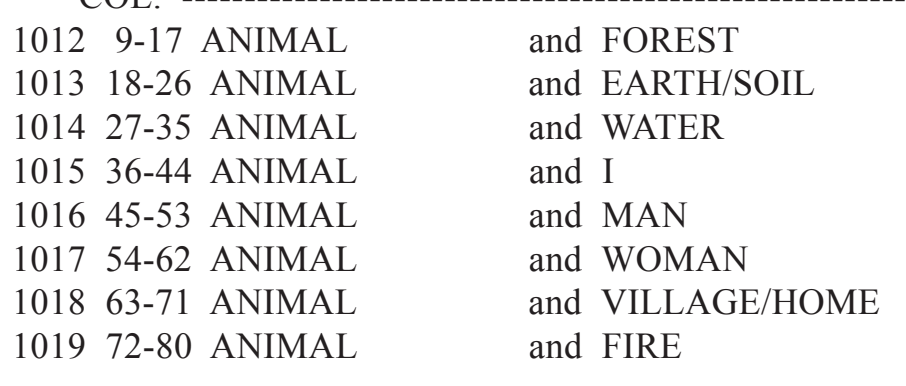

black and white

$$
\text { COL. }
$$

1020 9-17 ANIMAL

1112 18-26 FOOD

$1113 \quad 27-35$ FOOD

1114 36-44 FOOD

1115 45-53 FOOD

1116 54-62 FOOD

1117 63-71 FOOD

1118 72-80 FOOD

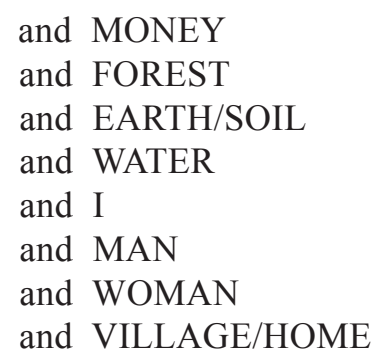

and MONEY

and FOREST

and EARTH/SOIL

and WATER

and I

and MAN

and WOMAN

and VILLAGE/HOME

black and white

$$
\text { COL. }
$$

$1119 \quad 9-17 \quad$ FOOD

$1120 \quad 18-26$ FOOD

$1213 \quad 27-35$ FOREST

1214 36-44 FOREST

1215 45-53 FOREST

1216 54-62 FOREST

1217 63-71 FOREST

1218 72-80 FOREST

and FIRE

and MONEY

and EARTH/SOIL

and WATER

and I

and MAN

and WOMAN

and VILLAGE/HOME

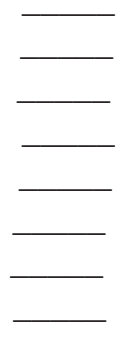

black and white

COL.

\section{9-17 FOREST}

$122018-26$ FOREST

1314 27-35 EARTH/SOIL

1315 36-44 EARTH/SOIL

1316 45-53 EARTH/SOIL

1317 54-62 EARTH/SOIL

1318 63-71 EARTH/SOIL

1319 72-80 EARTH/SOIL

\section{and FIRE}

and MONEY

and WATER

and I

and MAN

and WOMAN

and VILLAGE/HOME

and FIRE

black and white

COL.

1320 9-17 EARTH/SOIL

1415 18-26 WATER

1416 27-35 WATER

1417 36-44 WATER

1418 45-53 WATER

1419 54-62 WATER

1420 63-71 WATER

1516 72-80 I

and MONEY

and I

and MAN

and WOMAN

and VILLAGE/HOME

and FIRE

and MONEY

and MAN 
black and white

COL.

$\begin{array}{lllll}1517 & 9-17 \text { I } & & \text { and WOMAN } & \\ 1518 & 18-26 & \text { I } & \text { and VILLAGE/HOME } & - \\ 1519 & 27-35 & \text { I } & \text { and FIRE } & - \\ 1520 & 36-44 & \text { I } & \text { and MONEY } & - \\ 1617 & 45-53 & \text { MAN } & \text { and WOMAN } & - \\ 1618 & 54-62 & \text { MAN } & \text { and VILLAGE/HOME } & - \\ 1619 & 63-71 & \text { MAN } & \text { and FIRE } & - \\ 1620 & 72-80 & \text { MAN } & \text { and MONEY } & -\end{array}$

black and white

COL.

1718 9-17 WOMAN

1719 18-26 WOMAN

1720 27-35 WOMAN

1819 36-44 VILLAGE/HOME

1820 45-53 VILLAGE/HOME

1920 54-62 FIRE

and VILLAGE/HOME

and FIRE

and MONEY

and FIRE

and MONEY

and MONEY

[These demographic data have been modified slightly, consistent with our experience in the field and with reference to standard Galileo formats]

What is your age?

What is your sex? $\quad($ male $=1$, female $=2)$

What is your occupation?

What is your highest level of education?

What is the name of your village?

How far away is the nearest forest?

Date in YYMMDD format

The interviewer's name 